\title{
Workshop Internacional "The Ties that Bind: Rethinking Dependences in the Medieval Iberian Peninsula and Beyond"
}

\section{Clara Almagro Vidal}

\section{(2) OpenEdition Journals}

Edición electrónica

URL: http://journals.openedition.org/medievalista/1792

DOI: 10.4000/medievalista.1792

ISSN: 1646-740X

Editor

Instituto de Estudos Medievais - FCSH-UNL

\section{Referencia electrónica}

Clara Almagro Vidal, « Workshop Internacional "The Ties that Bind: Rethinking Dependences in the Medieval Iberian Peninsula and Beyond" », Medievalista [En línea], 25 | 2019, Publicado el 17 marzo 2019, consultado el 23 septiembre 2020. URL : http://journals.openedition.org/medievalista/1792 ; DOI : https://doi.org/10.4000/medievalista.1792

Este documento fue generado automáticamente el 23 septiembre 2020

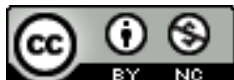

Mediavalista está licenciado com uma Licença Creative Commons - Atribuição-NãoComercial 4.0 Internacional. 
Workshop Internacional "The Ties that Bind: Rethinking Dependences in the Medieval Iberian Peninsula and Beyond"

Clara Almagro Vidal

NOTA DEL EDITOR

Data recepção do artigo / Received for publication: 08-10-2018 
Figura 1 - Cartaz de divulgação do Workshop Internacional "The Ties that Bind: Rethinking Dependences in the Medieval Iberian Peninsula and Beyond"
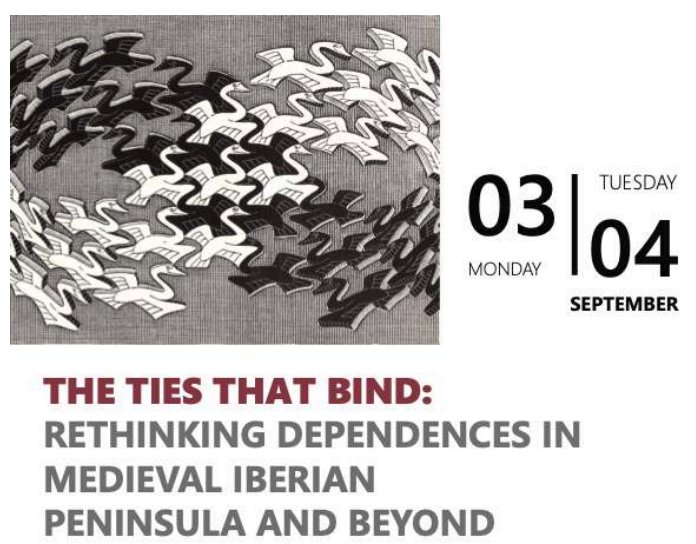

\begin{tabular}{l|l|l} 
UNIVERSIDADE \\
DE EVORA
\end{tabular} \mid $\begin{aligned} & \text { COLÉGIO DO } \\
& \text { ESPIRITO SANTO }\end{aligned}$

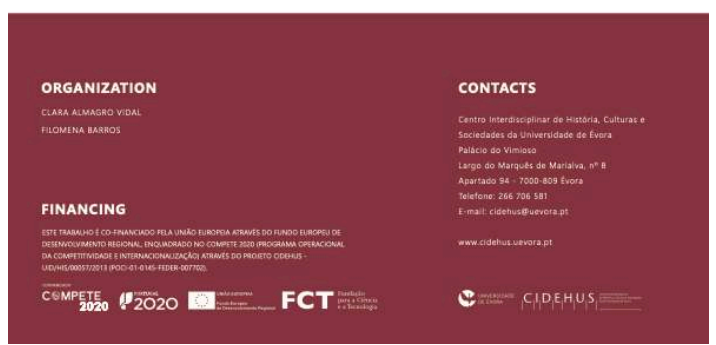

1 Tuvo lugar, durante los días 3 y 4 de septiembre de 2018, en el Colégio do Espírito Santo de la Universidade de Évora, el Workshop internacional "The Ties that Bind: Rethinking Dependences in the Medieval Iberian Peninsula and Beyond". Organizado con el apoyo de CIDEHUS ${ }^{1}$ y por la profesora Filomena Barros y la investigadora postdoctoral Clara Almagro, miembros de dicha institución, participaron en él un grupo de once investigadores de instituciones de España, Italia, Israel Portugal y Reino Unido, todos ellos con una trayectoria investigadora consolidada sobre el tema en cuestión.

Durante un día y medio, organizado en seis sesiones, los participantes presentaron los últimos avances en sus investigaciones sobre formas de servidumbre, esclavitud y otras formas de dependencia personal presentes en la cuenca del Mediterráneo en distintos momentos de la Edad Media, tanto en áreas de dominio cristiano como islámico.

3 La Península Ibérica centró buena parte de las intervenciones, aunque otros puntos del Mediterráneo también estuvieron presentes, proporcionando puntos de contraste y complemento que enriquecieron la discusión y situaron los casos peninsulares dentro de un contexto más amplio. Luís Filipe Oliveira (Univ. Algarve) presentó el caso de los musulmanes que dependieron de órdenes militares en el reino de Portugal, mientras que Clara Almagro Vidal (Univ. Évora-CIDEHUS) hizo lo propio para las de Castilla. Ambos casos mostraron los numerosos puntos en común entre ambos reinos, aunque también diferencias sobre las que conviene deliberar en el futuro. Siguiendo en esa misma línea, Filomena Barros (Univ. Évora-CIDEHUS) reflexionó sobre la terminología empleada para referirse a cautivos y esclavos en Portugal en los siglos XIV-XV, y Raúl González González (Investigador independiente) mostró cómo sí había esclavitud autóctona en el reino de Asturias entre los siglos VIII y XIII, aunque designada usando distintos términos. Por su parte, Cristina de la Puente (Instituto de Lenguas y Culturas 
del Mediterráneo-CSIC) y Uriel Simonsohn (Univ. Haifa) presentaron sendos trabajos que expusieron las complejidades legales dentro de las distintas ramas del Islam, con especial atención a la continuidad de dependencias entre esclavos y sus dueños después de la manumisión de los primeros, bajo la forma de obligaciones de trabajo, particularidades en el sistema de herencia, redes clientelares.

4 También sobre dominio islámico versó la contribución de Jesús Brufal (Univ. Lleida), quien presentó una comunicación sobre las transformaciones sociales que se sucedieron con paso de los reinos de taifas al dominio almorávide, con especial atención, por un lado, a la extracción social de los nuevos líderes comunitarios y, por otro, a los grupos cristianos. Una visión también general de las formas de dependencia, esta vez dentro de la sociedad sarda fue presentada por Luciano Gallinari (CNR- Istituto di Storia dell'Europa Mediterranea), mostrando un panorama muy particular debido al prolongado impacto de la dominación bizantina sobre la isla. También sobre un caso insular habló Aysu Dinçer (Univ. Warwick), en este caso sobre los siervos y esclavos rurales de Chipre durante el período de dominación de la casa de Lusignan y posteriormente de la República de Venecia. Por último, Raúl González Arévalo (Univ. Granada) exploró las conexiones y diferencias entre cautividad y esclavitud en la Castilla medieval y las motivaciones que pudo haber para aplicar una $u$ otra forma de dependencia. Todas estas contribuciones iniciaron animadas discusiones en las cuales se reflexionó sobre aspectos terminológicos y conceptuales de las formas de dependencia durante la edad media, las transformaciones y continuidades a lo largo del tiempo y las diferencias y similitudes entre distintas áreas geográficas.

Entre las ideas que fueron visitadas con mayor profundidad destacan la necesidad de considerar la dependencia personal no como un fenómeno dual (positivo/negativo en absolutos), sino mejor dentro de una gradualidad, aspecto que obliga a su vez a a abandonar viejas dicotomías (libertad/esclavitud) y a observar cuidadosamente los contextos históricos que caracterizam cada situación concreta. Otro punto en común sobre el que se reflexionó es la superposición de distintas formas de dependencia personal sobre la misma persona, las mecánicas que implicaba la dependencia compartida y los conflictos que podían surgir por esa razón. Asimismo, se resaltó la continuidad de las formas de dependencia incluso cuando ésta había sido formalmente interrumpida por la manumisión o por otro mecanismo. Dada la gran calidad de las comunicaciones presentadas al workshop, se ha decidido que se preparará una publicación a partir de las mismas, que esperamos vea la luz en el futuro próximo.

\section{NOTAS}

1. CIDEHUS - Universidad de Évora, en el ámbito de: UID/HIS/00057/2013 (POCI-01-0145FEDER-007702), FCT/Portugal, COMPETE, FEDER, Portugal2020. 


\section{AUTOR}

CLARA ALMAGRO VIDAL

Centro Interdisciplinar de História, Culturas e Sociedades, Universidade de Évora, 7000-809 Évora, Portugal

claralmagro@yahoo.com

https://orcid.org/0000-0002-6243-3034 